\title{
INDUSTRY 4.0 AND HIGHER EDUCATION IN CIVIL ENGINEERING
}

\author{
Yatchko Ivanov*, Ana Yanakieva And Robert KaZAndjIEV \\ Institute of Mechanics, \\ Bulgarian Academy of Sciences, \\ Acad. G. Bonchev St., Bl. 4, 1113 Sofia, Bulgaria, \\ e-mails: yadir_1@abv.bg; aniyanakieva@imbm.bas.bg; \\ e-mail: robert@imbm.bas.bg
}

\begin{abstract}
Last century, known as a century of Industry 3.0, was the time of important inventions (nuclear fission and nuclear energy; polymers; nano-, micronized and composite materials; computers and information technologies and etc.). The intensive development of IT generated the basis of today's Industry 4.0, widely used in robotics, electronics, and digital transformation. This provoked many changes in economics and the management of many activities and processes. Many industries employ digital presentations and digitalization of the management of their activities. Construction however falls behind the use of digital transformations. In recent times, our business should solve many problems related to the ecology and management of building waste, energy effectiveness of buildings, the introduction of intelligent management of the life cycle of buildings and facilities. We discuss in what follows the necessary modifications of the higher education in civil engineering and the commitment to observe the requirements of the European cart of qualification framework.

Keywords: Industry 4.0, construction, digital transformation, education, European cart of qualification framework.
\end{abstract}

\section{INTRODUCTION}

The last century was the century of the rapid development of technologies. This was the time when nuclear fission was discovered urging the harnessing of atomic energy. Series of high-resolution microscopes was designed to back up material science, and polymers, nano- and composite materials were emerged. Many Bulgarian scientists joined the community of inventors: Acad. Georgy

\footnotetext{
${ }^{*}$ Corresponding author.

DOI: 10.7546/EngSci.LVII.20.03.03
} 
Nadjakov discovered the electrets, the basis of Xerox design; Prof. Ivan Mitev established the $6^{\text {th }}$ heart tone; Acad. Angel Balevski and Prof. Ivan Dimov invented gas counter-pressure casting of metals; the American with Bulgarian roots, Prof. John Atanassov, designed the first computer thus initiating the development of information technologies and the emergence of the information society. On the other hand, the information technologies and the related digitalization of almost all branches of public activity became the World vector of the last decade.

The task of the present study is to outline the digital transformation implemented in construction and the subsequent trends in modern higher education so that the latter to be adequate to the modern requirements for sustainable construction. The requirements of modern business communications, the continuous need for information, data visualization, and business consultations, define the direction of development of the education in civil engineering, namely to provide knowledge of the implementation and use of IT and digital technologies. Consider the general business globalization, including the construction branch. Note that it requires that a civil engineer should possess knowledge of several areas: (i) digital technologies for the acquisition, processing, and analysis of data stimulating the development of sustainable construction; (ii) management of construction waste; (iii) energy efficiency; (iv) exploitation, management and renovation of buildings, facilities and monuments of material and cultural heritage.

\section{INDUSTRY 4.0 AND THE NEEDED MODIFICATIONS OF PROFESSIONAL SKILLS}

Industry 4.0 (The Fourth Industrial Revolution) was initially discussed at the World Economic Forum, Davos, Switzerland, 2015, and the Forum constituted in 2016 Center for Industry 4.0 in San Francisco. Forum Chairman, Klaus Schwab, noted that the technology of Industry 4.0 should involve hardware and software as well as cyber-physical/biological systems significantly contributing to the progress of global communications. The key tasks were to be the development of robots, artificial intelligence, nano- and biotechnologies, $3 \mathrm{D}$ printing, and autonomous cars.

The first definition of Industry 4.0 is "... an entirely new way of introduction of technology into society and the human body" [1]. Subsequent examples here are the correction of the human genome, machine learning, etc. Yet, today we hardly enter the Industry 4.0 era, Fig. 1, [2]. 


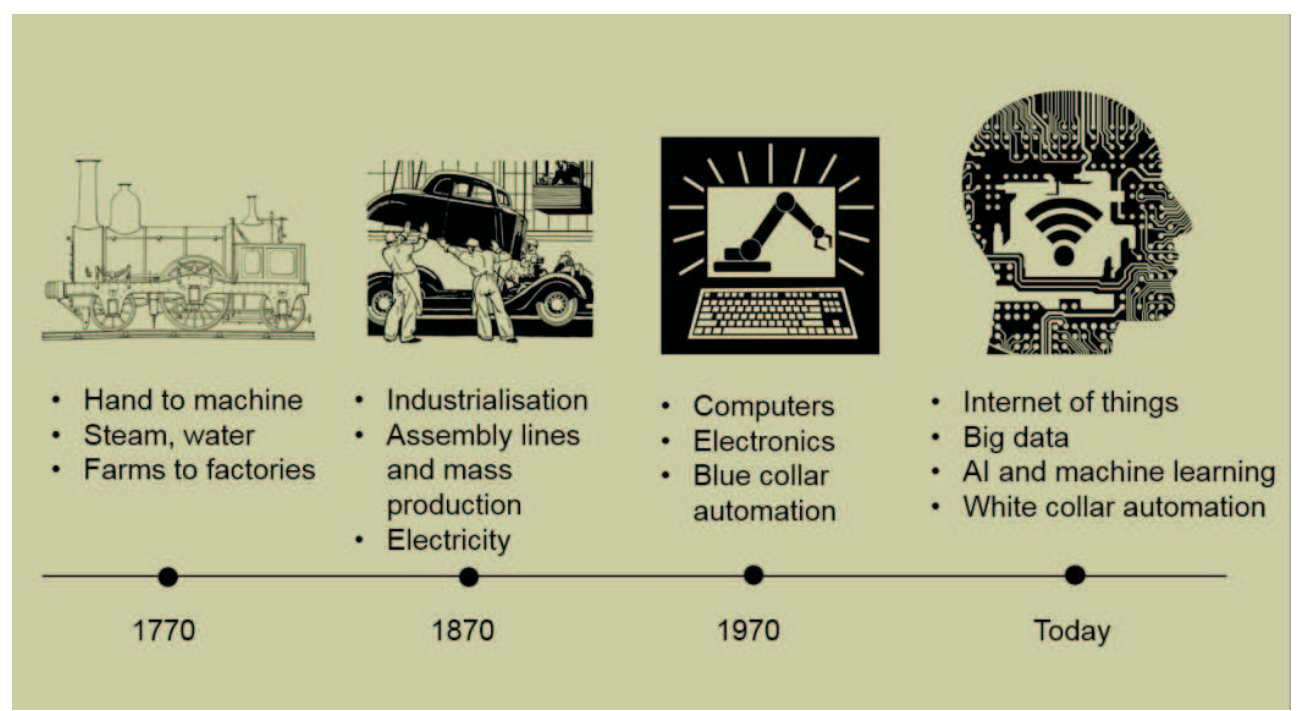

This information is an extract from Bernard Marr's webinar: Digital transformation: mega trends in the accountancy profession and ICAEW and Deloitte's e-Learning module Digital Era.

Fig. 1. Development and character of the industrial revolution [2]

Note however that the history of social-economic development proves the progress of mankind:

- Industry 1.0: Initiation of the "manual-machine" transfer of labor. James Watt invented the first steam engine for water pumping, and factories emerged.

- Industry 2.0: Industrialization time. Mass production and assembly lines. Discovery of electricity and electricity generation.

- Industry 3.0: Invention of computers. Electronics. So-called "Blue Collar Automation", involving physical and repeating standardized operations.

- Industry 4.0: The current industry intensively developing today. It involves automation technologies at a much higher level and much more qualified labor.

The term "White Collar Automation" was introduced to designate the use of artificial intelligence and intelligent machines in the execution of "high-level" human tasks.

Yet, researchers and specialists face a strong challenge in predicting the development of society, social and manufacture relations, science, and business, organization, and management of operations, etc. 


\section{DIGITALIZATION AND DIGITAL TRANSFORMATION}

S. Moor defined these new terms and related technologies. He commented in [3] the difference between digitalization and transformation, noting "... A brand new issue emerges as a result of digitalization, while automation improves something that has been already created". Later, R. Gartner specified "... Digitalization is the use of digital technologies in modifying the business model and generating new approaches and possibilities..." [4]. In other words, this is transition to a digital business. Note here that digitalization is in fact transformation of information into a digital form allowing its processing, acquisition, and transfer to users through a digital environment by using computer networks and the Internet. The information can be in the form of text, photos, audio and video files, and 3D samples [5].

Today digital transformation mostly involves the application of digital technologies to various fields such as business, management, administration, science, education, construction, etc., and it increasingly covers (although with different intensity) all areas of social-economic life. Its introduction depends on the character of the operations, the organization activities, the financial resources. No less is the role and intervention of the state, and the knowledge and experience of the work team [5].

\section{INDUSTRY 4.0 AND DIGITALIZATION OF CONSTRUCTION IN BULGARIA}

The development of IT was initiated in Bulgaria in the 1970s and 1980s. The first calculation code was developed in the 1980s-1990s, and a team of researchers developed a FEM code in the Higher Institute of Civil Engineering, Sofia (today University of Architecture and Civil Engineering). The first computing machine was designed at the Institute of Mathematics at BAS, and exhibited at a specialized Moscow exhibition. Powerful academic units such as Coordination Center for Informatics and Information Technologies and the Institute of Cybernetics and Robotics also emerged at that time, and computer design and manufacture started in Bulgaria. This was the time when National Computing Center for Construction, Institute of Construction Cybernetics, and Center for Construction Electronization were also founded. Various computing codes, such as NASTRAN, SAP IV, ABACUS, DINA, COSMOS/M were also developed.

Today, there are well developed and competitive IT companies designing software for business and e-trade digitalization. More than 10 companies also 
emerged offering software for companies producing building materials. Design companies employing modern IT operate comparatively successfully using specialized codes such as 3D, CAD/CAM, Auto Cad, CADAM, and modern codes for architectural design such as ArchCad, Revit, Rhinoceros, Sketchup. Lecturers use some of them in the teaching process. First steps to the use of Building Information Modeling (BIM) technologies are made. Yet, the examples of attempts to digitalize construction companies are still very rare. The same picture holds for business. A survey on the e-business of construction companies was made in Bulgaria by the $83^{\text {rd }}$ Work Group of the UN Commission for Sustainable Development, with the participation of Bulgarian Construction Chamber (BCC) and Bulgarian Scientific and Technical Union of Civil Engineering (BSTUCE). It proved that the exchange of electronic data concerning construction contracts was comparatively well developed in Bulgaria. The approved contracts are most often communicated electronically but the smaller contracts are not confirmed via e-mail. Moreover, the communication of contested contracts, work contracts, and project changes is rare. It was found that BIM and electronic cooperation in a project phase lacked. The survey also pointed out that the increase in BIM use would yield an increase in the electronic exchange of project information. The electronic exchange could raise the low degree of exchange of electronic documentation during project evaluation, contraction, and identification. Yet, the survey was not an object of a profound discussion by the local responsible institutions.

The discussions during the International exhibition "Architectural construction week 2020" organized by BCC and the Chamber of Architects resulted in the constitution of a special commission at the Ministry of Regional Development of Bulgaria with a task to develop a strategy for the development of construction digitalization in the next two years. The BSTUCE considers that the term is too long. It plans the organization of a round table discussion on construction digitalization in the fall of 2020. Thus, we must seek a unification of the efforts of all interested institutions in the acceleration of the Strategy development. On the other hand, the district department of BCC, Sofia, starts the organization of education courses for course employees of construction companies teaching the application of BIM. We note here with a great deal of frustration that the online series of teaching webinars "Digital transformation of construction", June 3-23 2020, was not practically attended by representatives of the leading construction companies. Surveys show that a larger number of design companies participate in education programs but they use a paper and not an electronic version of the documentation.

Engineering Sciences, LVII, 2020, No. 3 
The recent 3-4 years are noteworthy with a certain activity of the scientific community: several reports on that topic were delivered at the $10^{\text {th }}$ Jubilee International Conference on "Design and construction of buildings" DCB'2018 (Theory and practice for sustainable future) organized by BSTUCE, and at the International conference ARCivE'2019 (Higher School on Construction "Ch. Hrabar"). A special section of the $11^{\text {th }}$ Conference DCB'2020, September 2020, was dedicated to that problem. Knauf Bulgaria is the digitalization leader among companies producing building materials. It has a developed and functioning digitalization procedure applied to systems for dry construction [7].

\section{EUROPEAN CHART FOR QUALIFICATION FRAMEWORK}

Change of the work conditions due to the fast entry of digitalization into life, drastic climate changes, and the requirements for sustainable development initiated the development of UNESCO project "Education for sustainable development. Good practices". As stated, one of the tasks of higher education is students' preparation for a successful realization in the labor market, and students should be equipped with knowledge of the most recent scientific achievements. At the same time, the project stresses on current and future preservation of environment. Universities should offer high quality education combined with excellent practical skills in the field of sustainable development and the practical application of modern IT and digitalization. The future civil engineer should have generated capabilities to autonomous learning as an element of the skills acquired at graduation. He should also possess key competences formulated in the European Framework of Competences (2006/962/EU), including:

- Communication in the native language;

- Communication in foreign languages;

- Mathematical competence and basic competence in natural sciences and technologies;

- Digital competence (usage of digital technology in information, communication, data acquisition, transformation and analysis);

- Skills for individual learning;

- Special and civil competences;

- Sense of (and inclusion in) culture.

These competences are a good basis for the full realization of the young engineer - socially and personally. The individual learning skills combined with mathematical, scientific, and digital literacy guarantee professional mobility 
(gain of new professional skills) and easy adaptation to the rapidly changing needs of the labor market. Note also that the formation and development of the above skills is a process encompassing the entire life of a today engineer, but the educational system plays a crucial role [7-9].

Today, students, having acquired the outlined skills and competences and being prepared for the digitalization of the construction branch, would execute the EU and EP directives for economics based on the knowledge gained and on the decisions of the Bulgarian authorities for sustainable development of construction. Their work will be decisive for Bulgaria to join the leading states guaranteeing the sustainable future of Europe.

Locally, students' university training and introduction into sustainable construction begin with courses such as "Sustainable development", "Construction and ecology", etc. (Higher Civil Engineering School "L. Karavelov", Higher Civil Engineering School "Ch. Hrabar", European Polytechnic University, etc.). Part of the students in civil engineering studies certain disciplines in building waste recycling. The requirements for management of building waste demand inclusion of this issue into the subsequent projects. The necessity of including digitalization and digital transformations in the teaching programs has become more and more actual. Note the positive tendency however that all scientific events during the recent decade include topics on sustainable construction. Researchers focus on digitalization employment in the entire life cycle of buildings and facilities. HCES "Ch. Hrabar" is a typical example having organized a master class "Sustainable development - the innovative driving force of construction", while a new MS program "Strategy for sustainable construction and innovations" is upcoming. Note also the experience of Volkswagen, Slovakia [10] in the development of an MS program "Plus" which despite theoretical and practical knowledge cultivates communication skills, project management and teamwork. After two years of learning, students do a summer internship in plants acquiring practical skills, prepare their diploma theses during the fourth university year, and have a mentor during the first years of studying to gain knowledge of the entire process of car manufacture. The program is in support of the high motivation of young engineers. This motivates the purposeful investment in workers' skills in France where employees pass 3, 6, and 12-months qualification courses in the university, discontinuing work. Moreover, they solve practical problems and develop topics posed by their companies. 


\section{EDUCATION DURING THE COVID 19 PANDEMIC}

Since the beginning of 2020, the world fights the spread of the COVID infection. Since March 2020, Bulgarian students are out of the classrooms, auditoriums, and laboratories. Problems and deficiencies accumulate. The current problems in teaching especially of civil engineers are loss of direct contact between students, teachers, and colleagues; violation of the teamwork; difficulties in formulation, discussion, and evaluation of term papers and projects by the teachers; difficulties in the control of lecture attendance and practical exercises; difficulties in carrying out laboratory exercises. All these adversities violate the normal rhythm of education. What should we do to guarantee qualitative training of future civil engineers? What should be their new competences and skills considering digitalization and the pandemic overcoming? We need a new complex knowledge of construction business and a new business model and market positioning of construction companies. This implies the gain of new skills to process a significant volume of information during the management of the life cycle of buildings and facilities.

The pandemic posed the problem of intensification of the education through digital communication [11, 12], expansion of the electronic [13] and distant education [14], and the virtual teaching technologies [15]. All these forms of education have their advantages but pose problems as well. However, the accumulation of subsequent experience and data is forthcoming.

\section{CONCLUSIONS}

We marked, in brief, the basic changes owing to Industry 4.0 and the digitalization of civil engineering education. We also outlined specific trends of education under the COVID 19 crisis. Yet, we should note the numerous challenges and the needed persistent work to guarantee an adequate education of civil engineers, thus justifying the future success of the construction branch.

The modification needed of the teaching process and the introduction of construction digitalization should be realized coherently and promptly. The application of IT to construction management should become a routine practice.

\section{REFERENCES}

[1] K. SCHWAB, http://www.foreinaffairs.com/articles/2015-12-12/forth-industrial. 
[2] Bernard Marr's webinar: Digital transformation: mega trends in the accountancy profession and ICAEW and Deloitte's eLearning module Digital Era, 2018, https://www.icaew.com/technical/technology/finance-in-a-digitalworld/digital-transformation/digital-transformation-mega-trends.

[3] S. Moor, http://www.gartner.com/smarterwithgartner/digitalization-or-automation.

[4] R. Gartner, https://www.gartner.com/en/documents/3267726.

[5] F. Filipova, Transformation of accounting and audit, Jubilee International Conference "Economics science, education and real economy: Development and interaction in digital age" Publishing House "Science and Economics", Economics University, Varna (2020) 100-113, ISBN 978-954-21-1040-8 (in Bulgarian).

[6] R. Eadie, N. Stankov, Ya. Ivanov and J. Perera, State of E-business in Bulgarian construction industry, Pub. of TG 83 of Commission of NU, Sidney (2016) 36.

[7] Ya. Ivanov, Digital transformation - needed by construction, Proceedings of $16^{\text {th }}$ International Scientific Conference "Science and Digitalization of Business, Education and Tourism", 7-9.09.2020, p. 103 (in Bulgarian).

[8] Ya. Ivanov, Building industry and digital transformation, Proceedings of Jubilee International Conference "Economics science, education and real economy: Development and interactions in digital age", EU-Varna, 2020, 2, p. 247.

[9] YA. Ivanov, Opinion on modern economic reality and the training requirements on high education specialists, Proceedings of Nat. round table "Sustainable resource management in the contemporary economic reality", EU-Varna, 2019, p. 171

[10] B. Handulova, Noblesse oblige, Bulg. Industry Assoc. (2019) 67.

[11] M. Lambova, Digitalization - blessing or curse for the statistical education, Proceedings of Jubilee International Conference "Economics science, education and real economy: Development and interactions in digital age", EU-Varna, 2020, 1, p. 147.

[12] E. Kumanova, Education through digital communication, Proceedings of Jubilee International Conference "Economics science, education and real economy: Development and interaction in digital age", EU-Varna, 2020, 4, p. 370.

[13] V. Stoyanova, Distance E-based learning - opportunities and problems, Proceedings of Jubilee International Conference "Economics science, education and real economy: Development and interactions in digital age", EU-Varna, 2020, 4, p. 449

[14] http://mon.bg/bg/news/3883.

[15] M. Dragicevic Curcovic, Virtual technology based learning, Proceedings of Jubilee International Conference "Economics science, education and real economy: Development and interactions in digital age", EU-Varna, 2020, 4, p. 387.

Received November 06, 2020

Engineering Sciences, LVII, 2020, No. 3 